\title{
OPHTHALMIC CAUSES OF HEADACHE AMONG PATIENTS ATTENDING TERTIARY CARE GENTER IN KATHMANDU, NEPAL
}

\author{
Pranisha Singh, Anu Mishal, Jay Sundar Sunarait
}

Department of Ophthalmology, Nepal Medical College Teaching Hospital, Attarkhel, Gokarneshwor-8, Kathmandu, Nepal

\begin{abstract}
The purpose of this study was to evaluate the ophthalmic causes of headache among patients attending tertiary care hospital. This was a descriptive, cross sectional hospital-based study. One hundred and thirty-two patients with ocular cause of headache excluding primary headache and pediatrics patients during one year were included. Detail ocular examination was done including visual acuity, refraction, binocular vision assessment like convergence insufficiency and fusional insufficiency, anterior and posterior segment examination. Among headache patients, female was $106(80.3 \%)$ and male was $26(19.7 \%)$. The prevalence of headache in female was $6.9 \%$ and in male was $2 \%$. Headache was more common in age group 18-29 (59.8\%). The mean age of presentation was $29.9 \pm 10.2$ years (range 18-61 years). Out of 132 patients with headache, 104 (78.8\%) had refractive error, 15 (11.4\%) had fusional insufficiency, 6 (4.5\%) had convergence insufficiency, 10 (7.6\%) had anterior segment diseases and $5(3.8 \%)$ had posterior segment diseases. Among refractive errors, both eyes astigmatism was the commonest 48 (36.5\%) followed by both eyes simple myopia $44(33.4 \%)$ which was statistically significant with ocular headache $(p=0.000)$. Ocular anomalies other than refractive error may coexist with headache complaints. Therefore, thorough ocular examination should be done in all patients suffering from headache.
\end{abstract}

\section{KEYWORDS}

Headache, ocular causes, refractive error, astigmatism

Received on: April 18, 2021

Accepted for publication: August 15, 2021

\section{CORRESPONDING AUTHOR}

Dr. Pranisha Singh,

Assistant Professor

Department of Ophthalmology,

Nepal Medical College and Teaching Hospital, Attarkhel, Gokarneshwor-8, Kathmandu, Nepal Email: prani_s@hotmail.com

Orcid No: https://orcid.org/0000-0001-8459-6515

DOI: https://doi.org/10.3126/nmcj.v23i3.40383 


\section{INTRODUCTION}

Headache is defined as continuous or prolonged dull pain in the region of the head. Headache in itself is not a disease but a symptom of a disease. Headache can be sight or life threatening if not treated promptly. It can be primary or secondary. Primary headache is not associated with underlying diseases whereas secondary headache is associated with underlying diseases. Among secondary headache, ocular cause is the most common cause of headache. Due to a close link between the eyes and headaches, Ophthalmologists are usually the first physicians to evaluate the patients with headache and headache associated visual disturbances. Most of the cases of ophthalmic origin is refractive error who first present to neurologists and undergo unnecessary investigations leading to waste of time and money which could be avoided if an Ophthalmologist is consulted initially..$^{1,2}$ In Ophthalmology Out Patient Department (OPD), the most common cause of headache is refractive error followed by other ocular causes. Therefore, the purpose of this study was to evaluate the ophthalmic causes of headache in patients attending the Ophthalmology OPD.

\section{MATERIALS AND METHODS}

The study was conducted in Ophthalmology OPD at Nepal Medical College Teaching hospital (NMCTH) from January 2020 to December 2020. One hundred and thirty-two patients with ocular cause of headache were studied. Sample size was taken using the formula $\mathrm{Z}^{2} \mathrm{pq} / \mathrm{d}^{2}=(1.9)^{2} \mathrm{X} 36$ $(100-36) / 8^{2}=3.61 \times 36 \times 64 / 64=129$. This was a descriptive, cross sectional hospital-based study. Patients above 18 years who presented to OPD with complain of headache was included in the study. Patients with primary headache, pediatric patients and with history of ocular trauma were excluded. Informed consent was taken from each patient. Ethical clearance was taken from Nepal Medical College- Institutional Review Committee (NMC-IRC). All patients underwent a complete ophthalmic examination including visual acuity, refraction, orthoptic evaluation including measurement of near point of convergence and range of fusion which was measured by prism bar.

Diagnosis was made as defined below:

Convergence insufficiency: Near point of convergence $^{3}$ (NPC) $>6 \mathrm{~cm}$ and fusional insufficiency ${ }^{4,5}$ is defined as $<15$ Prism diopters base out prism and $<8$ prism diopters base in prism.
Anterior segment by slit lamp examination, posterior segment evaluation by +90D lens and other examinations such as Intraocular pressure measurement by applanation tonometer, neuro-ophthalmological examinations were performed as when needed. Data was collected in research proforma. Data entry and statistical analysis were done using SPSS version 16 . The chi-square test was used to find the association between categorical variables. $\mathrm{P}$ value $<0.05$ was considered significant.

\section{RESULTS}

\begin{tabular}{|c|c|c|}
\hline Sex & $\mathbf{n}$ & $\%$ \\
\hline Male & 26 & 19.7 \\
\hline Female & 106 & 80.3 \\
\hline Total & 132 & 100 \\
\hline
\end{tabular}

One hundred and thirty-two patients with ocular headache excluding pediatric patients attended Ophthalmology OPD from January 2020 to December 2020. The prevalence of ocular headache was $4.7 \%$. Among the headache patients, female was $106(80.3 \%)$ and male was $26(19.7 \%)$ (Table 1). Female patients were 4

Table 2: Age distribution of study participants

\begin{tabular}{|lcc|}
\hline Age (Years) & $\mathbf{n}$ & $\mathbf{\%}$ \\
\hline $18-29$ & 79 & 59.8 \\
$30-39$ & 29 & 22.0 \\
$40-49$ & 15 & 11.4 \\
$50-59$ & 7 & 5.3 \\
$60-69$ & 2 & 1.5 \\
\hline Total & 132 & 100 \\
\hline
\end{tabular}

Table 3: Occupation of the study participants

\begin{tabular}{|lcc|} 
Occupation & $\mathbf{n}$ & $\mathbf{\%}$ \\
\hline Students & 42 & 31.8 \\
Homemaker & 37 & 28 \\
Business & 18 & 13.6 \\
Officer & 12 & 9.1 \\
Farmers & 6 & 4.5 \\
Teachers & 3 & 2.3 \\
Others & 14 & 10.6 \\
\hline Total & 132 & 100 \\
\hline
\end{tabular}


Table 4: Association between location of headache and causes of headache

\begin{tabular}{|c|c|c|c|c|c|c|c|c|}
\hline 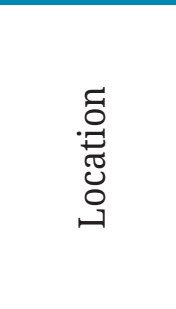 & 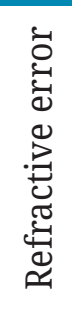 & 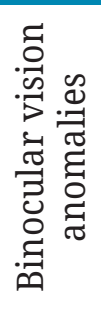 & 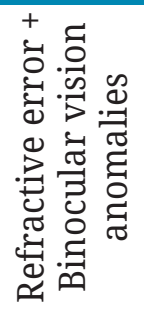 & 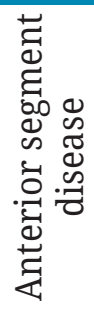 & 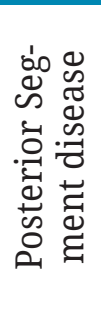 & 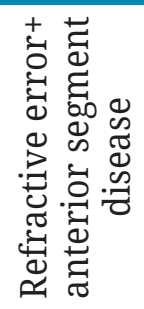 & $\underset{\stackrel{\pi}{ \pm}}{\stackrel{\tau}{0}}$ & 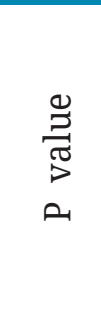 \\
\hline Frontal & 42 & 3 & 3 & 6 & 1 & 0 & 55 & \multirow{6}{*}{0.004} \\
\hline Temporal & 32 & 6 & 3 & 3 & 1 & 0 & 45 & \\
\hline Occipital & 13 & 2 & 0 & 0 & 1 & 0 & 16 & \\
\hline Parietal & 4 & 3 & 1 & 0 & 0 & 0 & 8 & \\
\hline Diffuse & 5 & 0 & 0 & 0 & 2 & 1 & 8 & \\
\hline Total & 96 & 14 & 7 & 9 & 5 & 1 & 132 & \\
\hline
\end{tabular}

Table 5: Ocular causes of Headache

\begin{tabular}{|lcc|} 
Ocular causes & n & \% \\
\hline Refractive error & 96 & 72.7 \\
Binocular vision anomalies & 14 & 10.6 \\
Refractive error + BVA & 7 & 5.3 \\
Anterior segment diseases & 9 & 6.8 \\
Posterior segment diseases & 5 & 3.8 \\
$\begin{array}{l}\text { Refractive error + anterior } \\
\text { segment disease }\end{array}$ & 1 & 0.8 \\
\hline Total & $\mathbf{1 3 2}$ & $\mathbf{1 0 0}$ \\
\hline
\end{tabular}

times more than the male. The prevalence of headache in female was $6.9 \%$ and in male was $2 \%$. Headache was more common in age group 18-29 (59.8\%) and then 30-39 (22\%) (Table $2)$. The mean age of presentation was 29.9 \pm 10.2 years (range 18-61 years). Fifty-eight patients with refractive error were in age 18-29 followed by 12 patients with binocular vision anomalies in same age group which showed statistically significant association between age and ocular headache $(p=0.00)$. Among 132 patients $59(44.7 \%)$ presented with only complain of headache. Twenty-five (18.9\%) came with blurring of vision, 17 (12.9\%) with dizziness, $16(12.1 \%)$ with ocular pain, 11 (8.3\%) with nausea and 4 (3\%) with vomiting in addition to headache. This study showed significant association between symptoms and causes of headache $(\mathrm{p}=0.000)$. Majority of cases $31.8 \%$ were students followed by $28 \%$ home maker and $13.6 \%$ were businessmen which showed statistically significant association between occupation and headache $(p=0.000)$ (Table 3). Frontal headache (41.7\%) was the commonest presentation followed by temporal (34.1\%) region. Forty-two patients with frontal headache had refractive error, 6 patients had anterior segment disease and 3 patients had binocular vision anomalies. There was

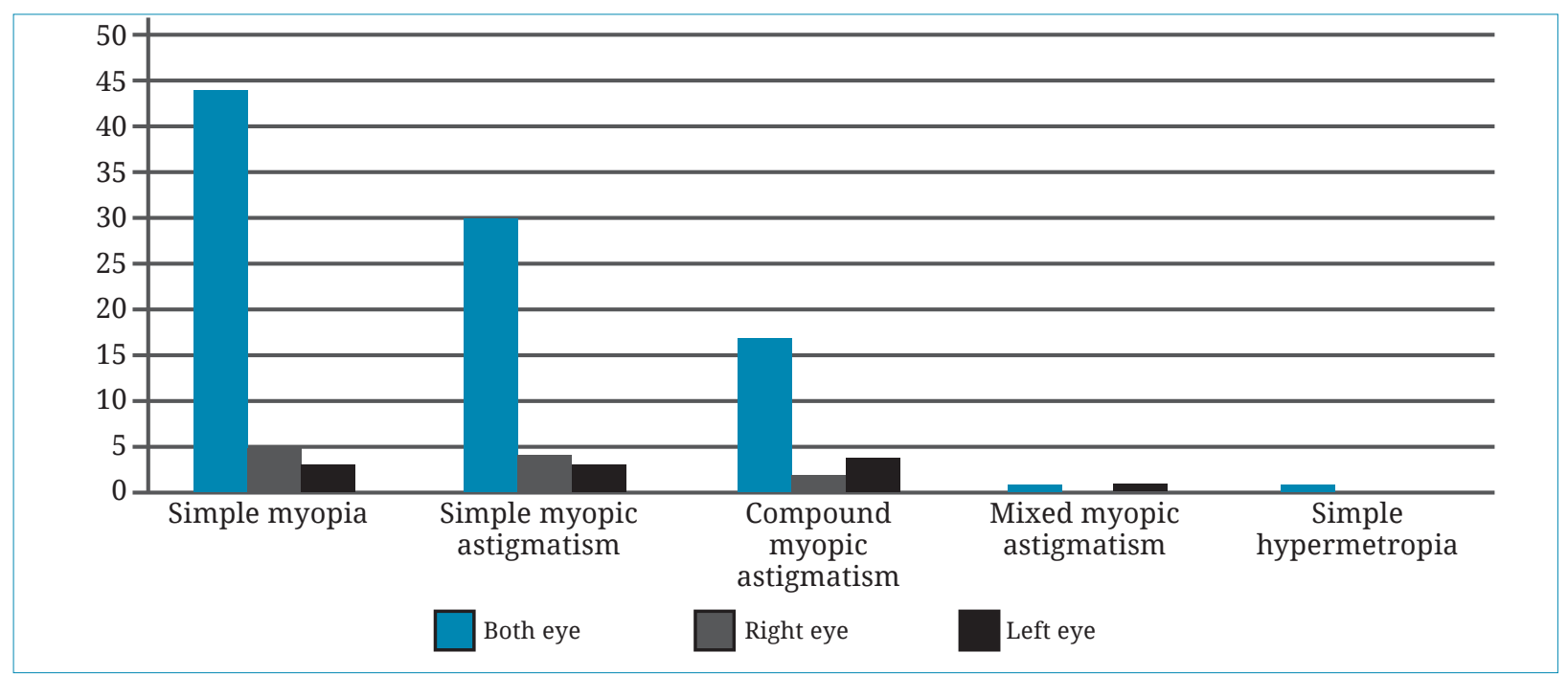

Fig. 1: Types of refractive error of study participants 
a significant association between location of headache and ocular causes of headache $(p=0.004)$ (Table 4).

Patients who had headache for $\leq 1$ week were $57(43.2 \%), 50(37.9 \%)$ had for $\geq 4$ weeks and $25(18.9 \%)$ had for $2-3$ weeks. There was no significant association between duration and causes of headache $(\mathrm{p}=0.18)$. Among 132 patients, 124 (93.9\%) had no systemic diseases whereas only $8(6.1 \%)$ were known cases of hypertension, diabetes and thyroid diseases $(\mathrm{p}=0.000)$.

Out of 132 patients with headache, 104 (78.8\%) had refractive error, 15 (11.4\%) had fusional insufficiency, $6(4.5 \%)$ had convergence insufficiency, $10(7.6 \%)$ had anterior segment diseases and 5 (3.8\%) had posterior segment diseases (Table 5). The prevalence of refractive error was 3.7\% among headache patients in our study. Out of 104 refractive error patients, 96 $\mathbf{( 7 2 . 7 \% )}$ had refractive error only and 8 patients had refractive error as well as binocular vision anomalies and anterior segment disease. Out of 10 anterior segment diseases, 8 (6.1\%) had glaucoma (4 glaucoma suspect, 2 phacomorphic glaucoma and 2 acute angle closure attack) and $2(1.5 \%)$ had anterior uveitis. Posterior segment diseases included $3(2.3 \%)$ cases of optic neuritis and 2 (1.5\%) of papilledema which was statistically significant with cause of headache $(\mathrm{p}=0.000)$.

Among refractive errors, both eyes (BE) astigmatism was the commonest 48 (36.5\%) followed by BE simple myopia 44 (33.4 \%) which was statistically significant with ocular headache $(p=0.000)$. In present study, $30(22.8 \%)$ had BE simple myopic astigmatism, 17 (12.9\%) had BE compound myopic astigmatism, 1 (0.8\%) had $\mathrm{BE}$ mixed astigmatism and $1(0.8 \%)$ had BE simple hyperopia. Where as in 11 patients, in Right eye (RE) simple myopia was seen in 5 (3.8\%), simple myopic astigmatism in $4(3 \%)$ and compound myopic astigmatism in 2 (1.5\%). In Left eye, simple myopia and simple myopic astigmatism was seen in $3(2.3 \%)$ respectively, $4(3 \%)$ compound myopic astigmatism and 1 (0.8\%) mixed astigmatism was seen (Fig. 1).

\section{DISCUSSION}

The present study showed that among headache patients, female was $106(80.3 \%)$ and male was $26(19.7 \%)$. Female patients were 4 times more than the male. The prevalence of headache in female was $6.9 \%$ and in male was $2 \%$. This finding was similar to other studies done by Garg $\mathrm{P}^{6}$, Hendricks et $\mathrm{al}^{7}$ and Marasini
S et $a l^{8}$ with females having more than twofold prevalence over males. Some other studies also showed females were more in number (59.4\%) than males (41\%). ${ }^{9,10}$

In this study headache was more common in age group 18-29 (59.8\%). The mean age of presentation was $29.9 \pm 10.2$ years (range 18-61 years) was statistically significant with ocular headache $(p=0.00)$. In Garg $P^{6}$ study $45.2 \%$ patients were young adults of 21-30 years. Similar findings were reported by Dhir ${ }^{11}$ and Ahmed and Zuberi ${ }^{12}$ who found the maximum incidence of headache in the age group of 2030.

This study showed majority of cases $31.8 \%$ were students followed by $28 \%$ home maker and $13.6 \%$ were businessmen which showed statistically significant association between occupation and headache $(\mathrm{p}=0.000)$. Kondam and Reddy ${ }^{13}$ observed that $28 \%$ of participants were students who came to hospital for headache. Similarly, in Fasih et al ${ }^{14}$ study students were the majority of the participant who reported to the hospital with headache contributing to $48 \%$ followed by housewives $25 \%$. Brown and Kronfeld ${ }^{15}$ also reported $60 \%$ of student having headache in their study.

Regarding the site of headache, our study showed that frontal headache $(41.7 \%)$ was the commonest presentation followed by temporal (34.1\%) region. Forty-two patients with frontal headache had refractive error, 6 patients had anterior segment disease and 3 patients had binocular vision anomalies (BVA). There was significant association between location of headache and ocular causes of headache $(\mathrm{p}=0.004)$. Similar to our study, Garg et al ${ }^{6}$ also showed $45.2 \%$ of patients presented with frontal headache. Similarly, Marasini et al ${ }^{8}$ study also showed frontal headache was more common and refractive error was associated with frontal headache. It is believed that uncorrected refractive errors are often associated with frontal and or occipital headache. ${ }^{16}$

In our study among 132 patients 59 (44.7\%) presented with only complain of headache. Seventy-three $(55.2 \%)$ came with blurring of vision, dizziness, ocular pain, nausea and vomiting in addition to headache. Similar to our study Whittington et $a l^{17}$ reported that among more than 1400 consecutive patients attending for refraction, $45 \%$ complained of headache. But our finding was not similar to Hassib MI et $a l^{18}$ study where only $19.15 \%$ patients came in Eye OPD with only complain of headache and $45.1 \%$ patients came with complain of dimness of vision, nausea, vomiting, redness 
and watering of eye in addition to headache.

The Prevalence of ocular headache in our study was $4.7 \%$ which was less than that reported by other studies. The prevalence of headache in general population is thought to around $48.9 \% .{ }^{19}$ Masoodi et $a l^{20}$ reported that the overall prevalence of any headache was $66.2 \%$ with female preponderance. Prevalence of headache from a nationwide study in Nepal has shown the prevalence to be $85.6 \% .{ }^{21}$ But the literature for a strong association between oculo-visual problems and headache is weak. ${ }^{22}$ This could be because of the patient enrolment being very selective in our study where all the non-ocular causes of headache and pediatric patients were excluded.

Headache is more prominent in low grades of refractive error than in high errors and more prominent in astigmatism in comparison to myopia and hyperopia. The constant effort exerted in order see clearly causes eye strain which results to headache. In present study, the prevalence of refractive error was 3.7\% among headache patients which was more (1.48\%) than prevalence of refractive error in headache patients done in Jain AP study. ${ }^{23}$ In present study out of 132 patients, 104 (78.8\%) patients with headache had refractive error. In Fasih $\mathrm{U}^{14}$ study maximum number of patients who presented with the complaint of headache had refractive errors 62 (16.36\%). Similarly, Kimbo $\mathrm{DK}^{24}$ reported $44 \%$ patients with refractive errors presented with headache.

Out of 104 refractive error patients, 96 (72.7\%) had refractive error only and 8 patients had refractive error as well as binocular vision anomalies and anterior segment disease. Among refractive errors, $\mathrm{BE}$ astigmatism was the commonest 48 (36.5\%) followed by BE simple myopia 44 (33.4 \%) which was statistically significant with ocular headache $(p=0.000)$. Similar to our study Marasini et $a l^{8}$ showed $44 \%$ had refractive error among whom astigmatism was more frequent (63.63\%) followed by hyperopia (27.27\%) and myopia (9.09\%). Similarly, in Jain S et al ${ }^{10}$ study, ocular headache was found in $36 \%$ and refractive error $(65 \%)$ was the most common cause of headache. Among refractive error astigmatism was found in $41 \%$ which was the commonest cause of headache. Ahmed and Zuberi ${ }^{12}$ also found astigmatism in 59\% and hypermetropia in $11 \%$ patients with headache. In a study by Kondam et al ${ }^{13}$ astigmatism (29.2\%) was the main cause of refractive error which caused headache. About 23\% were myopic and 14\% of hypermetropia was seen in study subjects. In Parajuli ${ }^{25}$ study, similar to our study astigmatism (69.5\%) was the most common type of refractive error followed by myopia (17.3\%) and hyperopia (13.05\%) causing headache.

In present study among astigmatism, 30 (22.8\%) had BE simple myopic astigmatism, 17 (12.9\%) had BE compound myopic astigmatism, $1(0.8 \%)$ had BE mixed astigmatism whereas $\mathrm{RE}$ simple myopic astigmatism in 4 (3\%) and RE compound myopic astigmatism in 2 $(1.5 \%)$ was seen. In Left eye $3(2.3 \%)$ simple myopic astigmatism, 4 (3\%) compound myopic astigmatism and $1(0.8 \%)$ mixed astigmatism was seen. Unlike our study, Jain et $a l^{10}$ study showed the most common type of astigmatism was simple hypermetropic astigmatism (16\%) followed by simple myopic astigmatism (14.5\%) and compound myopic astigmatism (6.5\%). Mechanism of headache from ciliary muscles contraction in hypermetropia of equal or different degrees where patients accommodate to see clearly and in astigmatism, especially of low degree or moderate degree, where muscles contract irregularly may cause more severe headache.

In our study, 15 (11.4\%) had fusional insufficiency, 6 (4.5\%) had convergence insufficiency. In a study by Marasini et al ${ }^{8}$ fusional vergence (11.25\%) and convergence insufficiency (16.25\%) were common among unstable binocularity. Similar to this, in Parajuli et $a l^{25}$ study $14 \%$ had convergence insufficiency and $3.5 \%$ had fusional insufficiency. Unlike our study Garg et al ${ }^{6}$ study showed $39.9 \%$ had convergence insufficiency causing headache.

In present study $10(7.6 \%)$ had anterior segment diseases and 5 (3.8\%) had posterior segment diseases. Out of 10 anterior segment diseases, 8 (6.1\%) had glaucoma and 2 (1.5\%) had anterior uveitis. Similarly, Kimbo et al ${ }^{24}$ study has mentioned $12 \%$ patients with anterior segment disease such as glaucoma and uveitis had headache. Other studies on headache have reported role of different ocular disease like acute glaucoma, uveitis, optic neuritis. ${ }^{26}$ Any ocular inflammatory disease and acute rise in intraocular pressure may cause pain in and around the eye and also cause headache. ${ }^{27}$ In our study posterior segment diseases included $3(2.3 \%)$ cases of optic neuritis and $2(1.5 \%)$ of papilledema which was similar to Parajuli et $a l^{25}$ study where $1 \%$ of optic neuritis and papilledema was noted.

In conclusion, refractive error was found to be the most common cause of ocular headache. Among refractive error astigmatism was the commonest cause of ocular headache. So, careful ophthalmic examination including 
refraction, binocular vision abnormalities test, anterior and posterior segment examinations of eye in all patients suffering from headache should be done. We recommend patients with headache to have ocular examination first as it is less invasive, less expensive and more sensitive.

\section{ACKNOWLEDGMENT}

We express our gratitude towards patients for their kind cooperation and resident doctors for their help during this study.

Conflict of interest: None

Source of research fund: None

\section{REFERENCES}

1. Headache Classification Subcommitee of the International Headache Society: The International Classification of Headache Disorders. 2nd edition. Cephalalgia 2004; 24 : 9-160.

2. Olesen J, Burst R, Ashina M, Tfelt-Hansen P. Origin of pain in migraine: evidence for peripheral sensitization. Lancet Neurol 2009; 8: 679-90.

3. Arnoldi K, Reynolds JD. A review of convergence insufficiency: what are we really accomplishing with exercises? Am Orthopt J 2007; 57: 123-30.

4. Wright KW, Spiegel PH. Pediatric Ophthalmology and Strabismus; second edition. Springer, New York 2003.

5. The Convergence insufficiency treatment trial study group. Randomized clinical trial of treatments for convergence Insufficiency in children. Arch Ophthalmol 2008; 126: 1336-49.

6. Garg P, Siddiqui A, Misra S, Gupta A. Association of Binocular Anomaly with Headache. Int'l $J$ Ophthal Res 2018; 4: 295-98.

7. Hendricks TJW, De Brabandar J, Horst FVD, Hendrikse F, Knottnerus AJ. Relationship between habitual refractive errors and headache complaints in school children. Opt Vis Sci 2007; 84: 137-43.

8. Marasini S, Khadka J, Sthapit PRK, Sharma R, Nepal BP. Ocular morbidity on headache ruled out of systemic causes - A prevalence study carried out at a community-based hospital in Nepal. J Optom 2012; 5: 68-74.

9. Uzma Fasih, Arshad Shaikh, Nisar Shaikh. Aetiology of headache in clinical ophthalmic practice at a tertiary care hospital of Karachi. $J$ Pak Med Assoc 2017; 67: 166-70.

10. Jain S, Chandravanshi SL, Dukariya L, Tirkey ER, Jain SC. Clinical study of headache with special reference to ophthalmic cause. Int'l J Med Sci Pub Health 2015; 4: 292-6.

11. Dhir BK. Convergence insufficiency. Indian $J$ Ophthalmol 1961; 9: 33-5.

12. Ahmed SH, Zuberi H. Depression anxiety and headache. J Pak Med Assoc 1981; 31: 276-9.

13. Kondam R, Reddy SR. A study to assess causes of headache in ophtmalmic practice in a tertiary care teaching hospital - A hospital based crosssectional study. Med Pulse Int'l J Ophthalmol
2017; 3: 45-47.

14. Fasih U, Shaikh A, Shaikh N. Aetiology of headache in clinical ophthalmic practice at a tertiary care hospital of Karachi. J Pak Med Assoc 2017; 67: 166-70.

15. Brown EVL, Kronfeld PC. The acuity of binocular depth perception in hemianopsia. Trans Am Ophthalmol Soc 1930; 28: 231-49.

16. Bellows JG. Headache and the eye. Headache 1968; 7: 165-70.

17. Whittington TD. The art of clinical refraction. London: Oxford University Press; 1958.

18. Hassib MI, Shoab AKM, Foez SA, Khan SH, Chowdhury AR. Clinical Evaluation of Headache Patients attended at Eye OPD in a Secondary Level Hospital in Bangladesh. J National Inst Neurosci Bangla 2016; 2: 75-78.

19. Stovner Lj, Hagen K, Jensen R. The global burden of headache: a documentation of headache prevalence and disability worldwide. Cephalalgia 2007; 27: 193-210.

20. Masoodi ZA, Shah PA, Iqbal I. Prevalence of headache in Kashmir Valley, India. Neuro Asia 2016; 21: 145-53.

21. Manandhar K, Risal A, Steiner TJ, Holen A, Linde $M$. The prevalence of primary headache disorders in Nepal: a nationwide populationbased study. J Headache Pain 2015; 16: 95.

22. Harle DE, Evans BJW. The correlation between migraine headache and refractive errors. Optom Vis Sci 2006; 83: 82-7.

23. Jain AP, Chauhan B, Bhat AD. Sociodemographic and clinical profile of headache-a rural hospitalbased study. Indian Acad Clin Med 2007; 8: 26-8.

24. Kimbo DK, Misotten L. Headaches in Ophthalmology. J Fr Ophtalmol 2003; 26: 143-7.

25. Parajuli S, Shrestha R, Chapagain S. Ocular causes of headache in patients presenting to a Sub-Urban Eye Hospital. J Ophthalmol Adv Res 2021; 2: 1-9.

26. Daroff RB. Ocular causes of headache. Headache 1998; 38: 661.

27. Roger L, Patrick J. Head and facial pain. In: Outline of Ophthalmology. British: John Wright and Sons Ltd. 1985: 64-5. 